\title{
LONG-TERM MONITORING AND COMPARATIVE ANALYSIS OF THE DURABILITY OF LIME-BASED RENDERS
}

\author{
ESKO SISTONEN, KALYANI KUMAR \& PETRI MUTANEN \\ Department of Civil Engineering, Aalto University, Finland
}

\begin{abstract}
The object of this article is to conduct analysis based on data from the probe monitoring of a rendered testing wall in Suomenlinna Sea Fortress, Helsinki, Finland. A special test wall was built in 2008 to make a comparison between different render types and recipes. The probe monitoring was started in July 2015 and for this article this data will be analysed. The changes of temperature, humidity and particularly the freeze-thaw cycles, which are typically the most crucial factor in the deterioration of renders in the Nordic climate, are included in the study. The monitoring data will be combined with results from the laboratory analysis and field test results to make a prediction on the future durability of each render. The renders will be compared with each other and the reference wall section to gain better understanding of the performance of the different types of render materials and the suitability of this kind of analysis on traditional rendering materials. Finding an accurate method to monitor traditional mortars like cement-based ones is potentially useful, which helps to understand the behaviour of the material and make recommendations for its repair.
\end{abstract}

Keywords: lime, hydraulic lime, mortar rendering, long-term monitoring, probe monitoring.

\section{INTRODUCTION}

Long-term monitoring of a material is essential to gain information on the condition and deterioration processes. For cement mortar renderings, there are well developed monitoring methods and computer programs to analyse the data. In principle, same techniques can be applied to traditional lime-based renderings too, but because the behaviour of the material is distinctly different, currently available building physics models cannot be used to analyse lime mortars. In 2015, a long-term monitoring project was started at Suomenlinna Sea fortress, Helsinki. The data was analysed, but when using the Wufi-program, all the parameters and formulas were required to be adjusted individually and the results were still unreliable [1]. Hydraulic limes, especially, have many similar characteristics with cements and their behaviour follow same kind of models, but some processes and their effects are inverse to cement and some qualities are unique just for limes. Therefore, it is expected that also traditional lime renderings and mortar be monitored and analysed in a similar way as cement, but they require specific physical models and have different emphasis on different parameters.

\section{LONG-TERM MONITORING OF THE TEST WALL}

In 2008, a specific test wall was built in Suomenlinna Sea Fortress in Helsinki, Finland, to compare the deterioration of different types of rendering mortars in harsh outdoor conditions. The wall is a free-standing brick structure and it has separate sections for different types of mortar renderings, which can be monitored in identical conditions (Fig. 1). The first complete deterioration analysis was conducted in July 2015 [1]. A part of this survey was to install Vaisala HMP44 probes to monitor the Relative Humidity (RH) and Temperature (T) of selected sections. Initial results were already used in early 2016, but the duration 


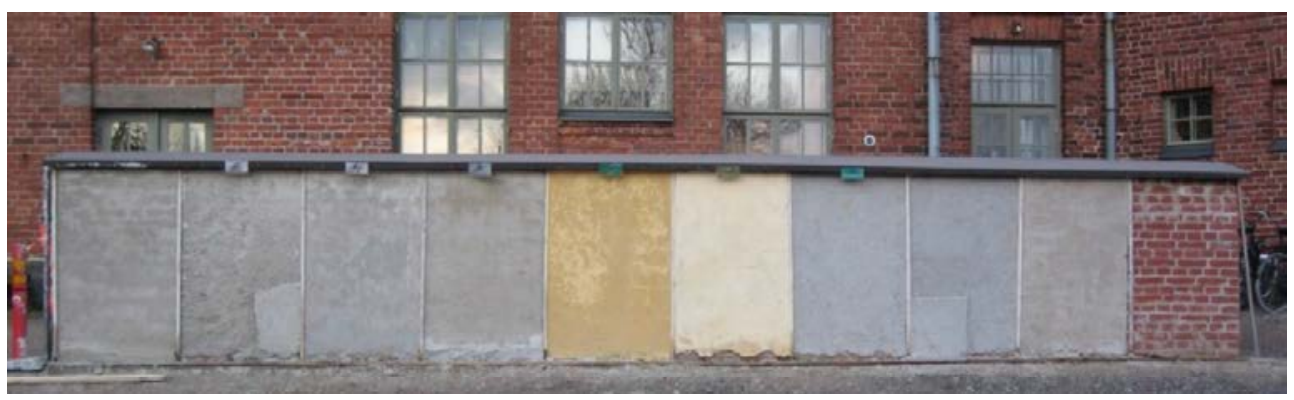

Figure 1: Original test wall in Suomenlinna Sea Fortress, as seen in July 2015.

of monitoring was still too brief to make any conclusions. However, this enabled detecting technical problems with the probes and understand the limitations of currently available software, which are all designed for modern construction materials. In the next phase of this project, the goal is to develop a model which enables the analysis of traditional mortar renderings with at least one commonly available building physics software. At this stage, the primary objective is to develop the method itself and assess its potential for future use in building conservation.

\subsection{The renderings of the test wall}

The test wall is a single brick English bond structure $(10 \times 1.5 \mathrm{~m})$ divided into ten sections with different renders on each side of the wall. Three sections were left unrendered to be used as reference. Thorborg von Konow designed thirteen different rendering mortar recipes. Four of them are based solely on air-hardening lime, one on lime-cement and seven are hydraulic made with St. Astier NHL 5 or slag furnace (Fig. 2). Most of the renderings are single layer, but three of them were rendered with three layers using the same recipes as for the single layer renders [2]. For some renders, the same binder was used to test different amounts of aggregate or binder. The location is in a courtyard and is not directly exposed to the sea, which is only 100 meters away. The Nordic sea climate, wind and salt ingress make the conditions harsh and demanding for all types of renderings.

\subsection{Method of long-term probe monitoring}

The probes were drilled to provide information on the contact layer of the bricks and renderings. They have two channels to measure voltages, which are converted into exact temperature and $\mathrm{RH}$ values after calibration of each probe. For this article, we use the monitoring data from $6^{\text {th }}$ of July 2015 till $7^{\text {th }}$ of November 2016, and some information from the thin sections and a condition survey in 2009 by Thorborg von Konow [2]-[5]. The test was originally the idea of Thorborg von Konow, who led the construction, but never found the resources to continue the research. Thus, there is no systematic information between 2009 and 2015. After the probes were installed in 2015, the site has been visited regularly to collect the data, repair technical problems and observe the visual signs of deterioration [6]-[9]. This has enabled to start long-term freeze-thaw analysis and manual interpretation of the effects of temperature and $\mathrm{RH}$ on these wall renderings. 


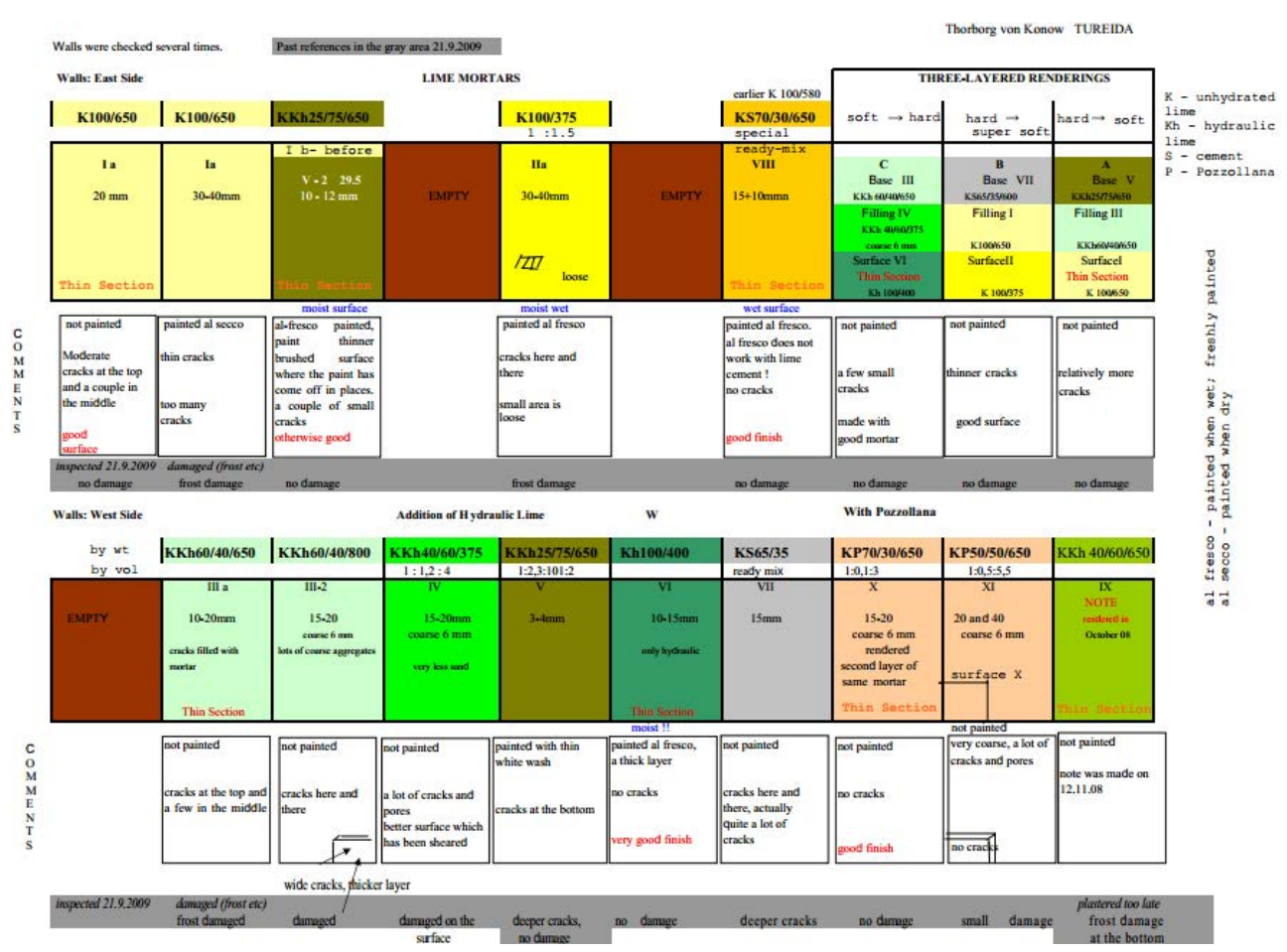

Figure 2: The condition survey of the test wall made by von Konow in 2009.

These results are compared and combined with the survey of 2015 (Chapter 4), which included visual inspection, microscopic camera analysis, hammering test, ultrasonic test, microscopic thin section analysis, carbonation test, water absorption/desorption test, tensile strength test, protective pore test, carbonation test, vapour diffusion test, rapid chloride migration test and building physics modelling with WUFI software. The use of these methods provides extensive technical information on the condition of each rendering. The probe data was converted and uploaded on excel, which was used for calculations and drawing the graphs. Now there is data for a period of 16 months, which makes the results relevant for the first freeze-thaw calculations of one whole year.

\section{ANALYSIS OF THE PROBE DATA}

The test wall has been visited regularly to collect the data, fix technical problems and to make a brief inspection of the site. This is the first time the probe data has been analysed and the next time will be after the winter of 2016-2017. Initially, collection of data from the East Side of the wall was a challenge, since the logger was facing some technical problems, which contributed to the loss of data for a substantial amount of time. However, after regular inspection, the problem was analysed and fixed, and the logger was changed, to gain continuous access to data, thereafter. Due to the lack of data from several months in the winter of 2015-2016, the results from the East Side of the wall are therefore presently not qualified to be a part of this paper. We will therefore be analysing the data and results only from the West Side of the Test wall (Fig. 3). 


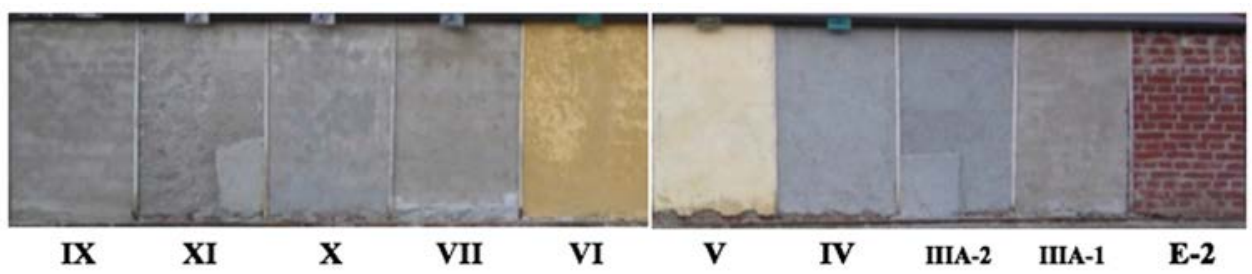

Figure 3: The West Side of the test wall with render section names.

The West Side of the test wall has nine rendered sections and one empty section. One of the sections in the middle of the wall is used to record the Ambient Air RH and Temperature (Fig. 4). Seven other sections were affixed with the probes to collect the data. The choice of sections qualified for data collection, was made based on the condition survey carried out in June 2015 [1]. We have collected this data over a period of 16 months, starting from July 2015 , and the data has been consistent for a fair analysis. The freeze-thaw cycles calculated based on this data reveal reliable results and can be used for further analysis.

\subsection{Temperature and relative humidity}

All the probes were calibrated before installation and, their gain and offset were recorded. This data was used to convert the values recorded as RH on the probe into Relative Humidity in Percentage. The temperature values recorded on the probes were changed to Temperature in Degree Celsius. This data was then plotted (Fig. 5) against time to reveal the temperature and relative humidity trends over 16 months.

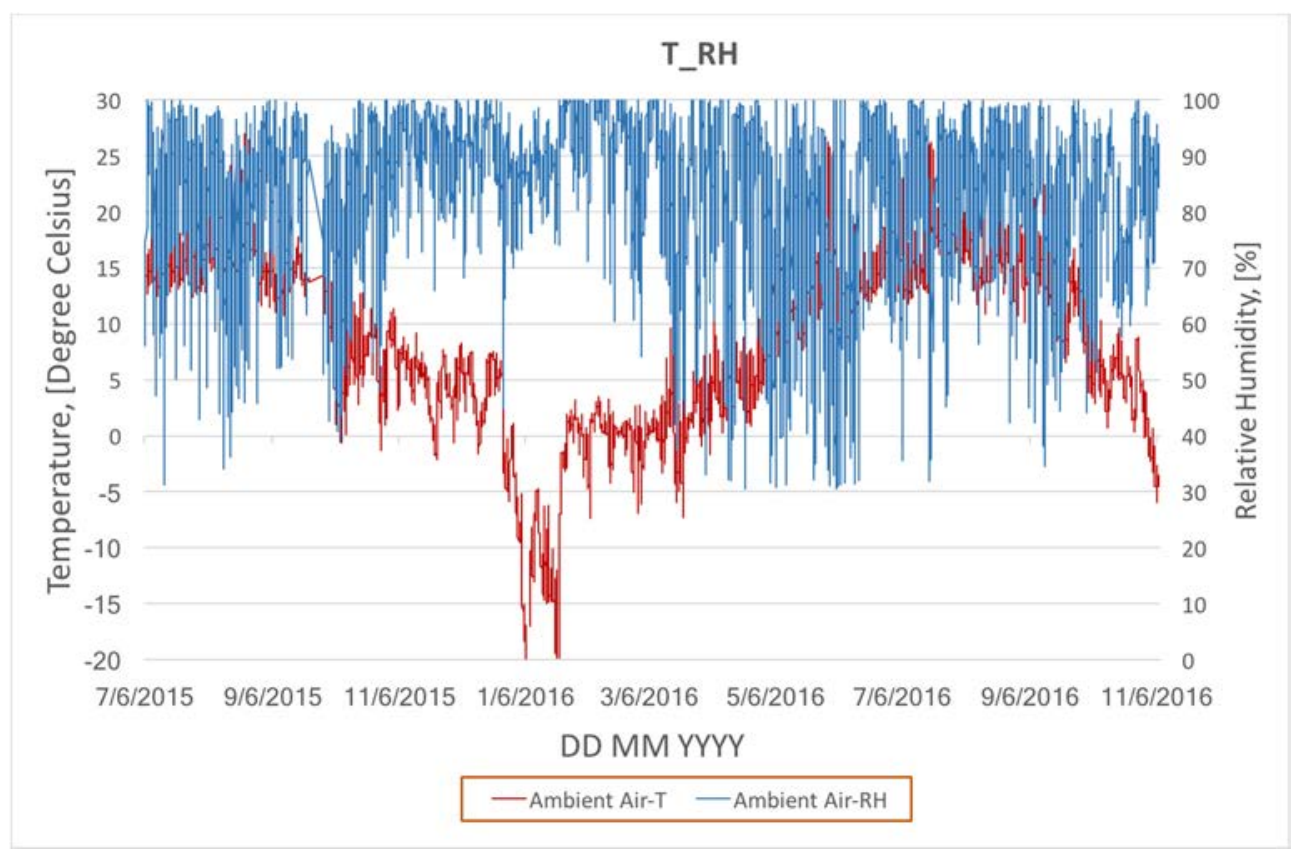

Figure 4: RH and temperature trends for West Side of test wall (ambient air only). 


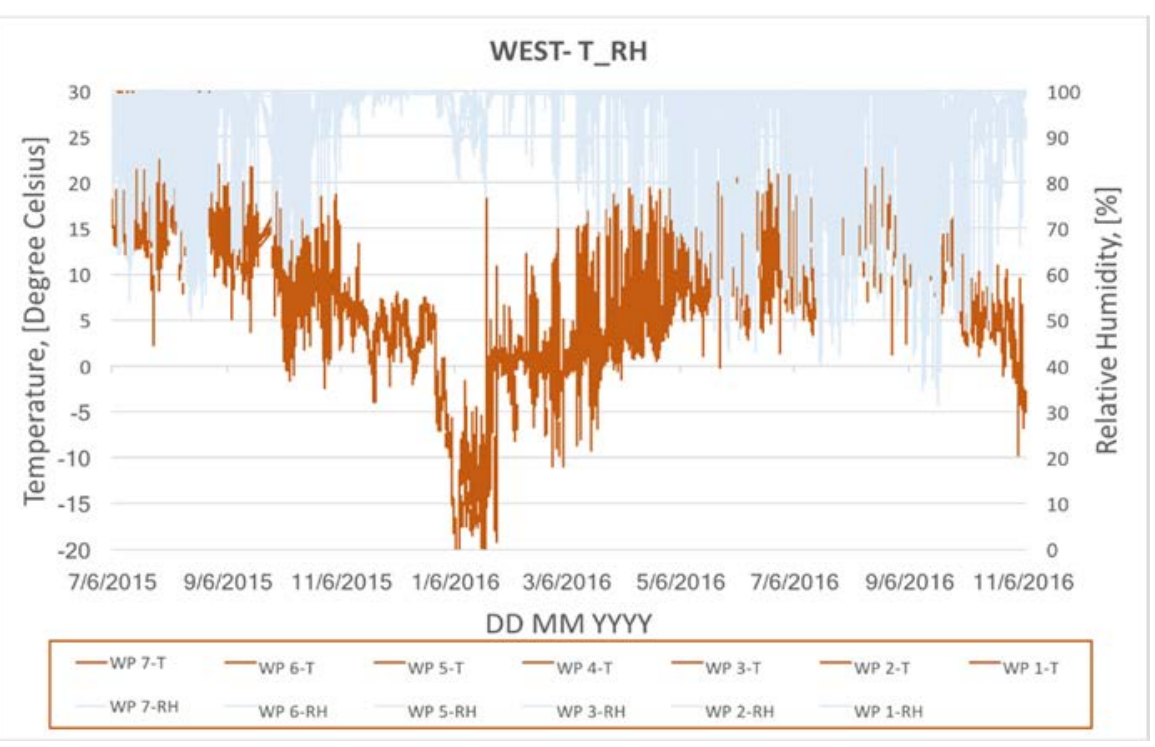

Figure 5: RH and temperature trends for West Side of test wall.

\subsection{Freeze-thaw cycles}

In cold climates, physical damage to concrete structures resulting from frost action is a major concern requiring expensive repair and maintenance. The problem is common to all porous materials but the degree of damage depends on the pore system. Damage caused by freezing and thawing appears as degradation of the surface, including severe cracking and internal damage extending into the concrete [10]. Various theories have been developed to discuss and explain the deterioration of concrete because of freezing and thawing, but such discussions are beyond the scope of this paper.

The winter of 2015-2016 was warmer than the average winter, therefore the number of freeze-thaw cycles is comparatively low. It is typical that in the spring the temperature varies a lot and this causes repeated FT-cycles when the temperature remains near $0^{\circ} \mathrm{C}$, which did not occur at large this winter. As per the ambient temperature, there were seven cycles. Most of the rendering sections also had between 6-8 cycles during this period (Table 1). The length of the cycles for each individual section, although not quite different, vary considerably.

Longer monitoring period is needed to make conclusions, but clear statistical differences are expected after these initial results. The boundary values for each cycle were $-5^{\circ} \mathrm{C}$ and $+2^{\circ} \mathrm{C}[10]$. At this point the main result is that the freeze-thaw calculations seem to provide realistic and detailed data, because there are clear differences in the interior temperatures when comparing the renderings to the ambient air and to each other. This is valuable information in long-term monitoring and would not be available without probe monitoring.

Table 1: Number of the freeze-thaw cycles on the West Side of test wall.

\begin{tabular}{|l|l|l|l|l|l|l|l|l|l|}
\hline SECTION & Empty-E2 & IIIA-1 & IV & V & VI & VII & IX & Ambient \\
\hline Probe name & WP 7-T & WP 6-T & WP 5-T & WP 4-T & WP 3-T & WP 2-T & WP 1-T & Ambient air-T \\
\hline Number of cycles & & 7 & 6 & 7 & 7 & 5 & 6 & \\
\hline
\end{tabular}




\section{ASSESSMENT OF SECTIONS AND PREDICTION OF THE DURABILITY}

Rendering acts as a conduit for moisture in the wall and it prevents the stone or brick masonry from decay induced by percolating water, moisture and salt solutions. The presence of water and its movement inside the pore network of renders is one of the most serious causes of deterioration. Structural deterioration is a complex phenomenon depending on various factors, which may often damage historical buildings and heritages [1].

In the spring of 2008 the test wall was constructed in Suomenlinna sea fortress with the idea of gaining data and results through experimental procedures which could be useful in gaining experiences working with different kinds of mortars and help in designing new repair mortars [1]. The assessment of the test wall started in June 2015 with a condition survey, as an incentive to study and understand this deterioration. The process started with visual inspection and then a series of tests were mapped out to record and analyse the extent of damage incurred by the test wall over the years of being constructed (Fig. 6). Samples for laboratory testing were collected by means of a diamond drilling machine. These specimens, after the possible laboratory tests, were used to prepare thin sections in the VTT laboratory and their analysis was done using Leica DMLP electronic microscope.

The condition assessment of the renders against different types of tests is presented in Table 2 [1]. The condition assessment was done based on the intensity of defects of the test wall mortars and each recipe was given a condition rating out of 6 . The higher values indicate higher intensity of defects and influence the overall condition of the wall surfaces. The average condition rating was calculated based on their performances in the in-situ and laboratory observations and tests [1]. We have tried to schematically represent the individual visually observed surfaces of the West Side of the test wall with their condition ratings and identification codes (Fig. 7).

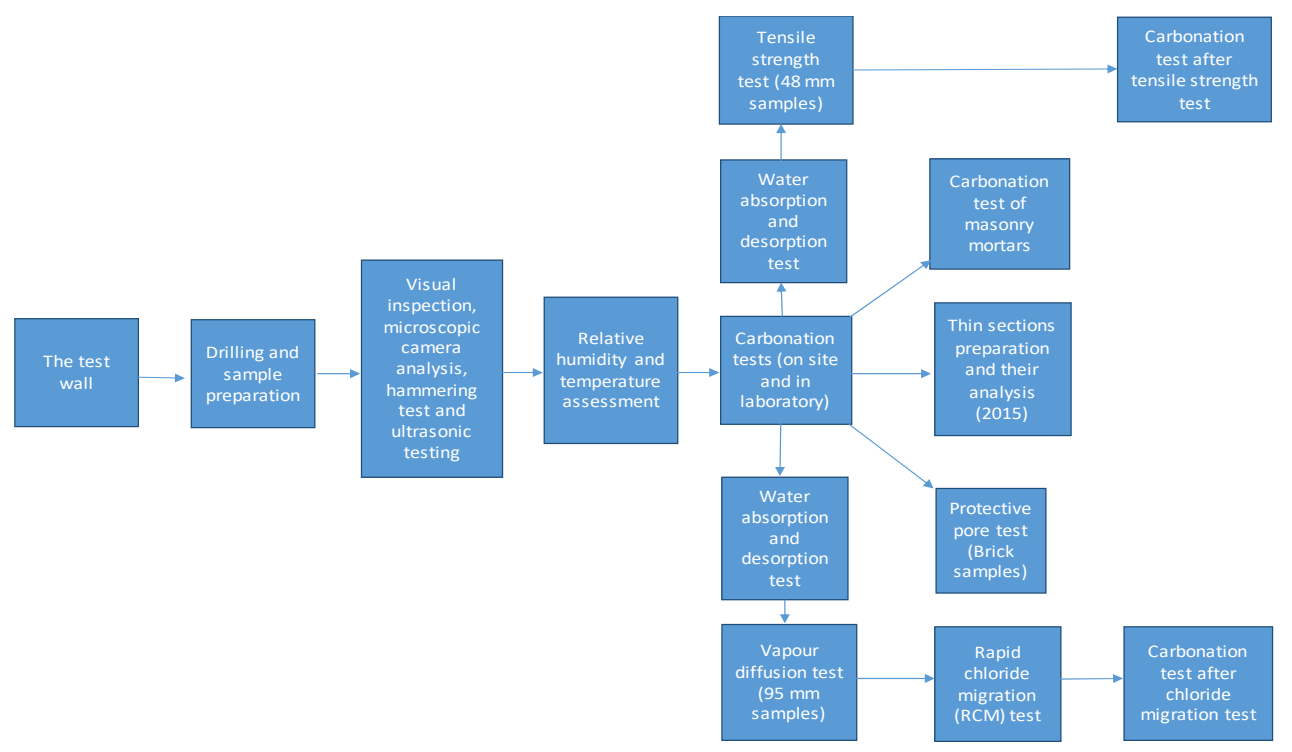

Figure 6: Flowchart demonstrating the order of performed experiments. 


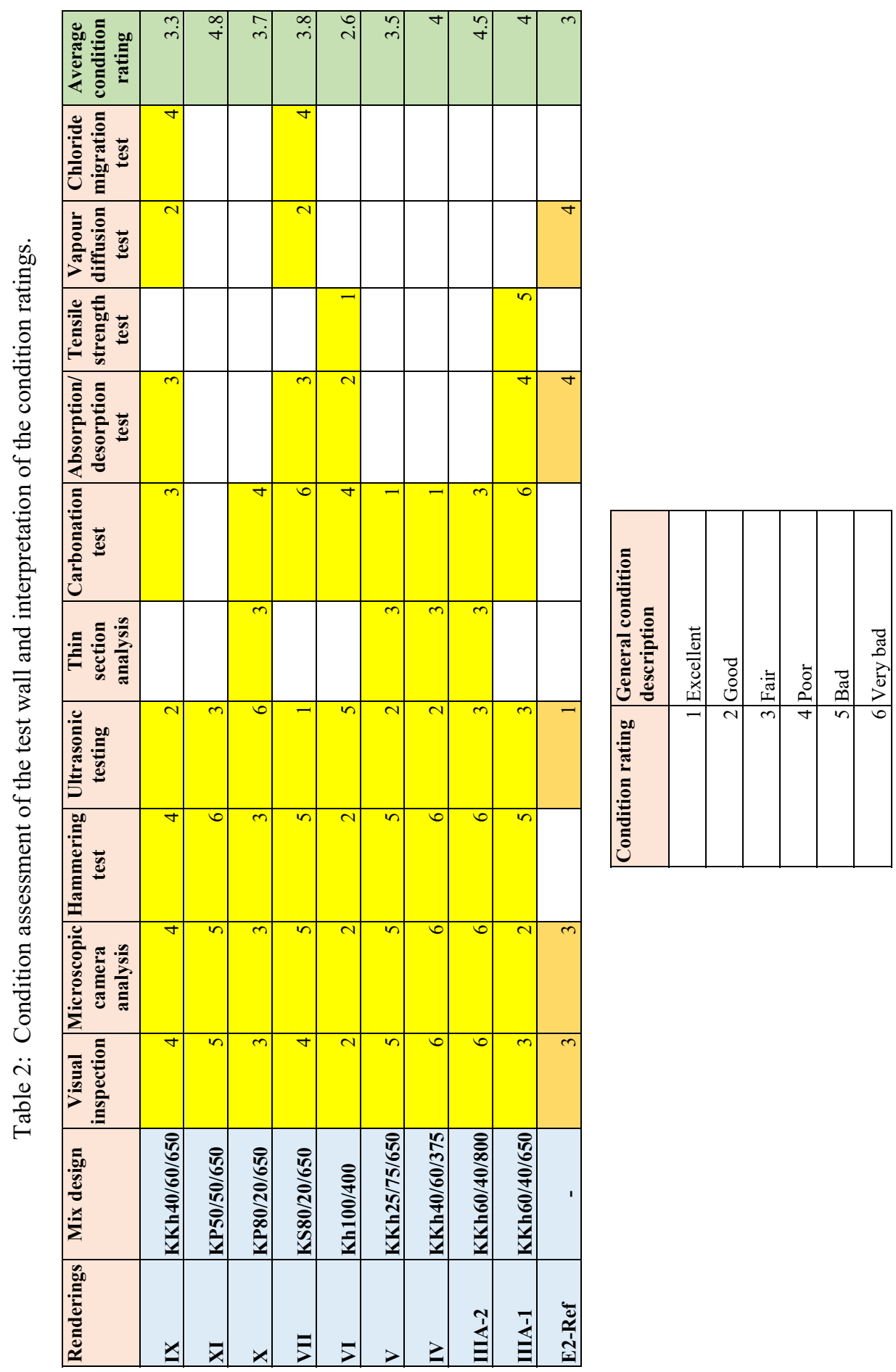



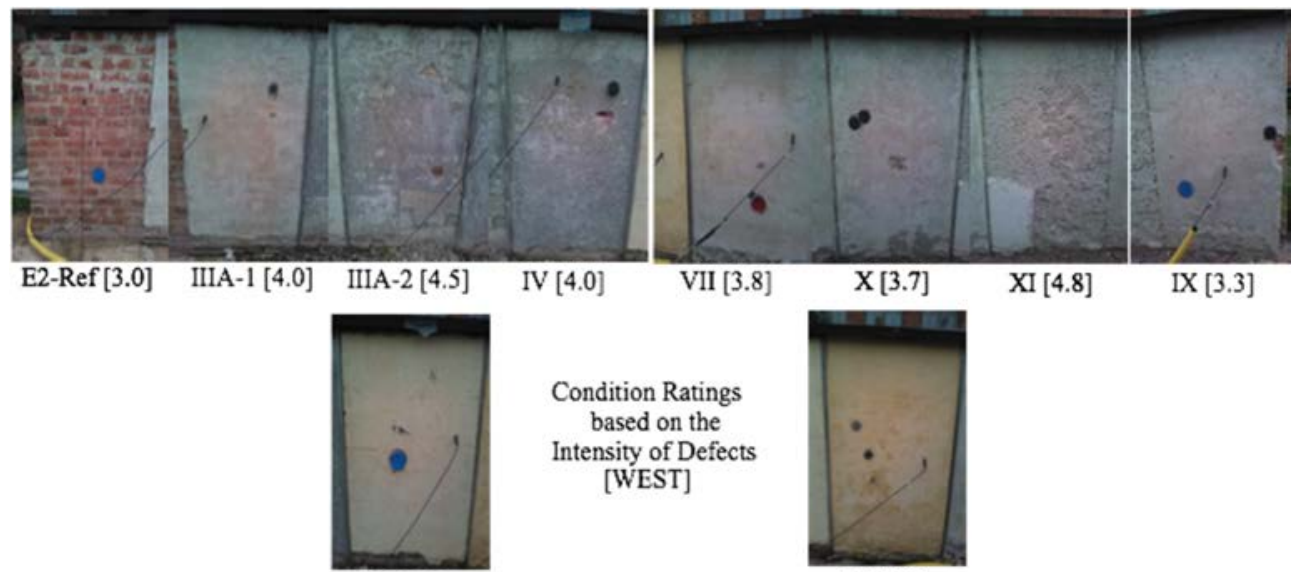

IV [4.0]
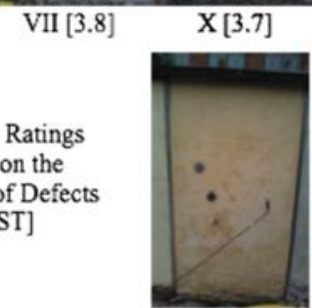

$\mathrm{V}[3.5]$

Condition Ratings based on the Intensity of Defects [WEST]

VI [2.6]

Figure 7: Schematic representation of condition ratings for the West Side of test wall.

Based on the laboratory tests performed on the samples collected in the summer of 2015, the condition of the render surfaces on the West Side of the test wall can be discussed. Mortar VII (Table 2), which was a ready-mix lime-cement mortar, was not painted and appeared to have lots of cracks on its surface. This mortar was fully carbonated and was in poor condition as can be seen from the condition assessment report. This mortar sample went through the most number of tests in this study and its high water-binder ratio caused it to perform poor in certain tests. Mortars X and XI were lime-pozzolana mortars and a drilled sample was not taken from mortar XI (KP50/50/650) because it was extensively damaged and drilling was not possible at all. It appeared to be in bad condition on visual inspection and thus, it performed very badly during the condition assessment as well. Mortar X (KP80/20/650) appeared to be in a good condition on visual inspection but it performed poorly in the laboratory tests although detailed experimental analysis was not carried out for this sample as it was also broken during drilling [1].

The remaining mortars IX, V, IV, IIIA-2 and III-A1 were hydraulic lime mortars and performed in similar manners. Mortar IIIA-2 appeared to be in bad condition even visually and its rough surface was due to the high amount of aggregates. Mortar had fallen from the wall in most parts of the section. The section was very hollow and could not support the drilling machine to extract the mortar sample so a hammered sample was taken from its surface. This mortar was based on the recipe with higher water-binder ratios compared to other recipes, which may be the reason behind its poor performance in tests such as tensile strength and water absorption. Mortar IV was made with the least amount of aggregates. It was quite deteriorated and broken during drilling and looked bad with many cracks all over its surface. Mortar V performed satisfactorily in the tests although it had lots of large cracks on its surface. Mortar IX was rendered in cold weather (November 2008) and its late rendering caused frost damage especially in the lower parts of the wall, but overall it performed well due to its good mix composition [1].

An average winter in Finland goes through 10-15 freeze thaw cycles over a span of at most six months [10]. The freeze-thaw analysis from the data obtained for the year 2015-2016 reflects to a comparatively milder winter, with the cycles ranging from 6 to 8 for most renderings on the west side. This indicates a mild, yet erratic trend in temperature 
change. The other renderings show cumulative durations near and below the average winter time.

Presently, with the accumulated data, it is unwise to make any further assessments about the other renderings, or do a comparative analysis. Figs 8 and 9 give an example of a less deteriorated render section on the west side of the wall. Fig. 8 shows the relative humidity and temperature trend for the same render over a period of 16 months.

\section{West Side: Section IV - WP 5-T}

(a)

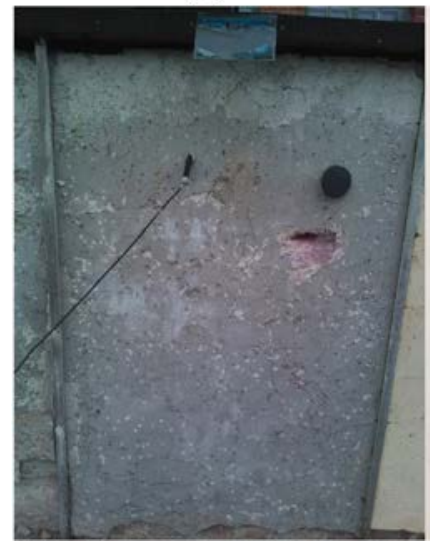

(b)

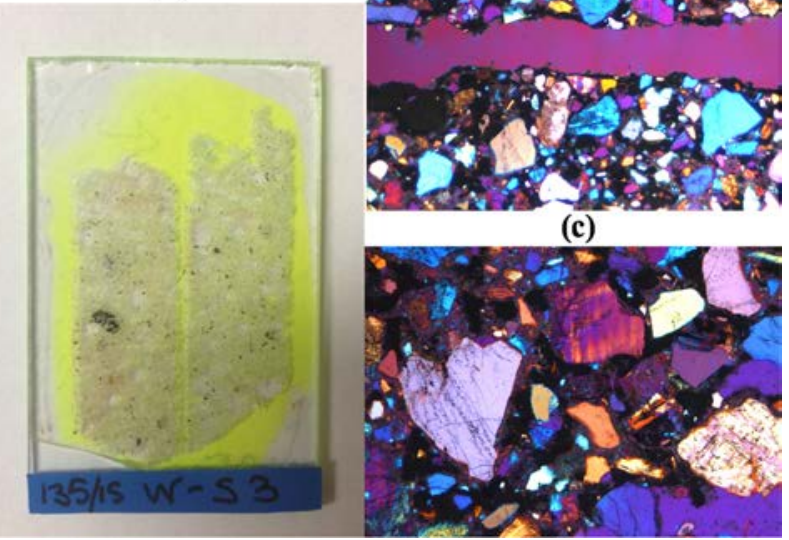

Figure 8: An example from Render Section IV of the West Side of test wall. (a) The rendering; (b) The thin section; (c) Microscopic images from the thin-section.

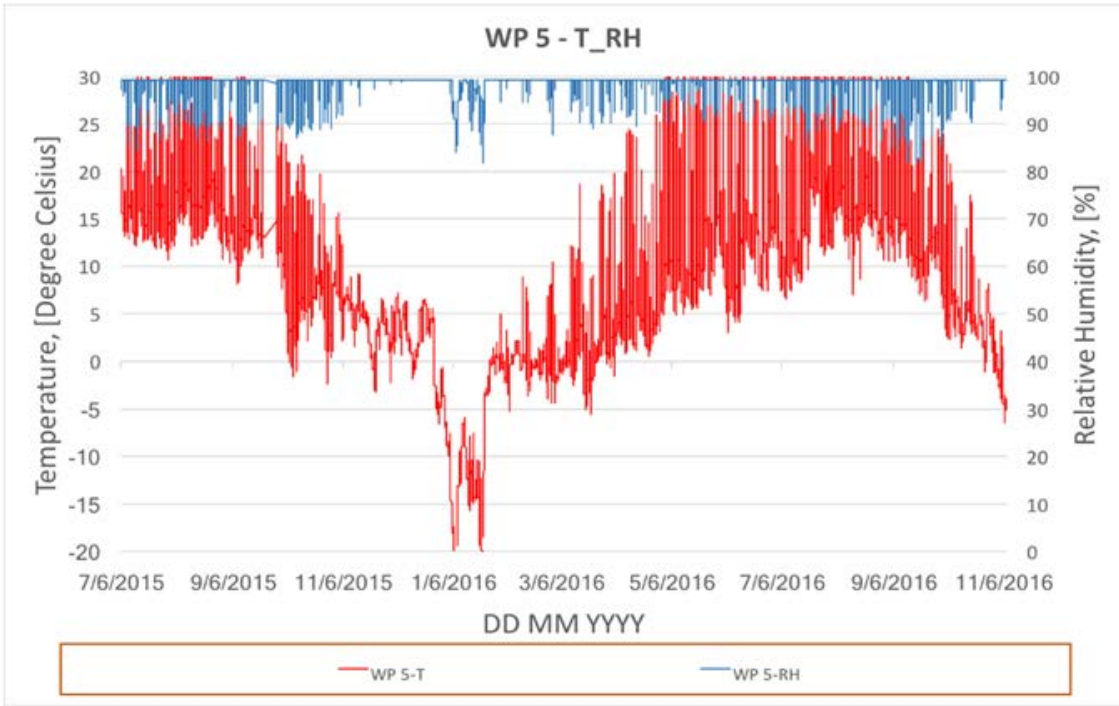

Figure 9: An example from Render Section IV of the West Side of test wall showing temperature and RH trends from July 2015 to November 2016. 


\section{SUITABILITY OF PROBE MONITORING ON TRADITIONAL RENDERINGS}

In Finland, probe monitoring has not been used with traditional lime or cement mortars, only modern cement renderings [11]. The method has clear advantages and disadvantages and should be used in combination with other testing methods, which can already be identified, although the concept is still under development.

\subsection{Advantages and disadvantages of probe monitoring}

The advantage of probe monitoring is that the deterioration mechanisms can be detected before they have caused significant damage. For example, rising RH indicates harmful level of moisture, which is the biggest cause of deterioration in the Nordic climate. Especially freezing and thawing are detrimental to renderings with excess moisture. Without probe monitoring, there is no exact way to measure this mechanism inside the structure. To predict the durability, it is beneficial to have information on the RH and number of freeze-thaw cycles within the structure. Ambient temperature is always different than inside the structure, therefore without monitoring the structure there is no exact way to calculate the cycles.

Long-term monitoring gives information for scientific research or in special cases, it is possible to do a thorough analysis of certain rendering. In Finland, most of the work with traditional mortars has lacked scientific knowledge specific to local conditions and building stock. Many mortar recipes have simply failed, but it is not clear why, although some good recipes have been developed since 1990s. To improve the practical conservation work, more scientific knowledge and methods to study the structures are needed. Probe monitoring seems like a potential way to introduce scientific methods into practice when dealing with bigger scale projects or otherwise special cases to estimate their durability.

Probe monitoring is potentially useful when testing new mortar recipes and techniques. So far different recipes have been compared by the signs of deterioration, but this requires long time exposure to the harmful conditions. It is also not clear, what has been caused by the material, environment or craftsmanship, which is essential especially to traditional renderings. Poorly made rendering starts to gain excess moisture from the beginning, but the deterioration can usually be detected only after several years. With probe monitoring, it is possible to identify this problem in advance, estimate the durability and make recommendations for repairs. When installing the probes to an existing rendering, excess moisture content can be detected with only a short monitoring period.

One of the common disadvantages of probe monitoring is that it requires more resources than is commonly available, therefore it can be used only for special cases and scientific study. Furthermore, it is not always evident that the results will be useful, especially if the probes have not been installed well. To gain enough scientific knowledge, the method should be tested on several cases, because historical structures are always unique cases. Moreover, the Test wall of Suomenlinna is just a simple wall and cannot simulate the way a heated building would. This far it has been only possible to test the concept itself, which needs to be developed further to identify the best combinations of different survey techniques.

\subsection{Sources of error}

Due to technical problems, some of the probes stopped working during the monitoring. The problem affected only the East side of the wall and some probes were replaced successfully. However, this caused gaps in the monitoring data. The probes themselves were already used and somewhat worn out. The team also needed to learn how to work with them. Because the monitoring has been going on only for 16 months, it is still too early to make final conclusions 
on the durability. Especially freeze-thaw cycles should be monitored over several winters to be able to make any conclusive statements.

More fundamental problem is the heterogeneous nature of the traditional renderings and structures. Probes can monitor only one specific area of the whole structure and choosing another location would give different values. For larger surfaces, it is necessary to install several probes to find out the differences. This requires experience and knowledge in the behaviour of traditional renderings. Skilled experts can detect the problems merely by visual inspection or by using other non-destructive methods.

\section{CONCLUSION}

In this study, we have studied the tests and observations performed on different render sections on the West Side of the test wall in Suomenlinna Sea Fortress, Helsinki, and developed the freeze-thaw cycles using the data recorded by probe monitoring of the same sections. The aim of the study was to analyse and compare the durability properties of the rendering mortars based on the in-situ and laboratory tests conducted in 2015-2016, as well as the freeze-thaw cycles obtained for this study. However, such a comparative analysis is difficult to be carried out and it is difficult to say that one mortar is better than the other, based only on the available data.

The test wall is about eight years old now and some mortars have already been in an extremely deteriorated condition. However, eight years is not a very long period considering the life of a building or structure. This study follows the first detailed assessment of the test wall carried out in the 2015-2016. For the same reason, we cannot make any assessment or comparisons solely based on the freeze-thaw cycles, due to the limited period of data collection and no existing data to compare our freeze-thaw results with. Any comparison made based on this would be unreliable at this point of time. However, the aim of the further study is to find a relevant connection between the existing laboratory analysis and the data collected by probe monitoring, and understand the long-term durability trend of these rendered sections on the test wall.

The construction of the test wall was a great approach to study and understand different kinds of mortars used in historical buildings and suggest appropriate repair methods for their conservation. This test wall is valuable and has a huge role in protection of historically important world heritage sites of the Suomenlinna Sea Fortress.

\section{REFERENCES}

[1] Gomdenn, P., Durability of renderings of historical buildings, Master's thesis, Aalto University, Finland, 94 pp. + app. 43 pp., 2016. http://urn.fi/URN:NBN:fi:aalto-2016 05262247

[2] von Konow, T., Rappauskokeet Suomenlinnassa, Tureida Oy (unpublished), Helsinki, 2009, (in Finnish).

[3] von Konow, T., The Study of Salt Deterioration Mechanisms Decay of Brick Walls Influenced by Interior Climate Changes, Suomenlinnan Hoitokunta: Helsinki, 141 s., 2002. ISBN 951-9437-29-0.

[4] von Konow, T., Suomenlinnan Muuraus Rappaus Saumaus - Korjaukset 1997-2004, Tureida: Helsinki (unpublished), 38 s., 2005 (in Finnish).

[5] Lind, T., Rauniot ja restaurointi, kestävyys, kauneus, kertovuus, Teknillisen Korkeakoulun Arkkitehtiosasto: Helsinki, 122 s., 2008 (in Finnish).

[6] Al-Neshawy, F., Sistonen, E. \& Mutanen, P., Von Konow Database (TvK-DB), Version 1.3, 2015. 
[7] Sistonen, E., Mutanen, P. \& Al-Neshawy, F., Development of a database for the Restoration Mortars - D.B. von Konow, $1^{\text {st }}$ International Conference on Ageing of Materials and Structures 2014 AMS'14, Delft, The Netherlands, 26-28 May 2014, pp. 40-47, 2014.

[8] Mutanen, P., Ikääntyvä laasti, iätön kivi - Hydrauliset laastit muurattujen rakenteiden restauroinnissa, Bachelor's thesis, Aalto University, Finland, 34 pp., 2014.

[9] Mutanen, P., Hydraulic lime mortars in conservation of historical structures in the Nordic climate, Master's thesis, Edinburgh School of Architecture and Landscape Architecture, University of Edinburgh, Scotland, 130 pp., 2015.

[10] Al-Neshawy, F., Computerised prediction of the deterioration of concrete building facades caused by moisture and changes in temperature, Aalto University publication series, Doctoral Dissertations 96/201, 2013. ISBN 978-952-60-5203-8.

[11] von Konow, T., Mortars in Old Structures (Laastit vanhoissa rakenteissa), eds K. Crumbach, S. Mentu \& A. Lönnberg (Chap. 8), translated to English in 2014. Financed by the Governing Body of Suomenlinna, 104 pp., electronic publication. http://www.kalkforum.org/uploads/pdf/litteratur/mortars-in-old-structures.pdf 